\title{
ОДИН ИЗ ВОЗМОЖНЫХ ПУТЕЙ ПОВЫШЕНИЯ ПРОИЗВОДИ- ТЕЛЬНОСТИ КАМЕРНЫХ СЛАНЦЕПЕРЕРАБАТЫВАЮЩИХ ПЕЧЕЙ
}

\author{
ю. В. ИВАНОВ, \\ кандидат технических наук
}

Увеличение производства искусственного-газа из сланцев является одной из существенных задач, стоящих перед промышленностью Эстонской ССР.

Для выполнения этой задачи эксплуатационным и исследовательским персоналом сланцехимического производства в настоящее время успешно ведутся работы по повышению производительности существующих камерных печей.

Нам представляется полезным в связи с этим ознакомиться с накопленным работниками производства опытом, обобщить его и постараться наметить правильные пути увеличения производительности камерных печей без изменения существующей технологии. Это приобретает интерес еще и потому, что уже запроектированы и будут строиться еще такие же заводы.

На протяжении длительного периода времени исследователями и инженерами-производственниками велась творческая работа над разрешением задачи промышленного получения из прибалтийских сланцев газа в больших количествах. В середине $30-x$ годов эта работа успешно завершилось созданием камерной печи для коксования сланца. К настоящему времени накоплен уже достаточный опыт надежной эксплуатации этих печей.

Творческая мысль исследователей продолжает работать над созданием новых, еще более эффективных и высокопроизводительных технологических схем. Инженерно-технические работники на производстве также продолжают работу по усовершенствованию процессов в действующих установках.

Хороший пример в работе по повышению производительности существуюших камерных печей показывает коллектив работников сланцеперерабатывающего комбината «Кохтла-Ярве» и Теплотехстанции в г. Кохтла-Ярве.

В связи с рассматриваемой в данной статье задачей о путях увеличения производства газа на существующих установках необходимо ознакомиться с частью работ, проведенных на комбинате «Кохтла-Ярве». 


\section{1. Материалы испытаний и данные по усовершенство- ванию камерных печей}

Основой существующей технологии химической переработки сланцев является термическая обработка. Сущность химических процессов переработки топлива заключается в том, что под влиянием нагрева происходят химические реакции превращения органических веществ топлива в новые вещества, отличные по составу от исходных. Не вдаваясь в химизм процессов переработки сланца, отметим только, что чем выше температура нагрева органического вещества и чем быстрее сно прогревается, тем глубже идут реакции разложения, тем больше получается газообразных и меньше жидких продуктов. Следовательно, вопрос о повышении производительности камерных печей по газу, без изменения существующед технологии, сводится к теплотехнической задаче передачи сланцу нанбольшего количества тепла на наивысшем температурном уровне.

Обратимся к схеме обогрева камерной печи, изображенной на фиг. 1, и вкратце ознакомимся с тепловыми процессами, происходящими в печи.

Генераторный газ и воздух, проходя регенераторы, нагреваются до температуры $800^{\circ}$ и через косые ходы поступают снизу вверх, в группу из восьми или девяти вертикалов, где, перемешиваясь с воздухом, газ сгорает. Газовое пламя высокой температуры излучением и частично конвекцией нагревает поверхность простенков. Процесс прогрева сланцевой загрузки осуществляется благодаря теплопроводности и конвекции.

Пройдя вертикал и несколько

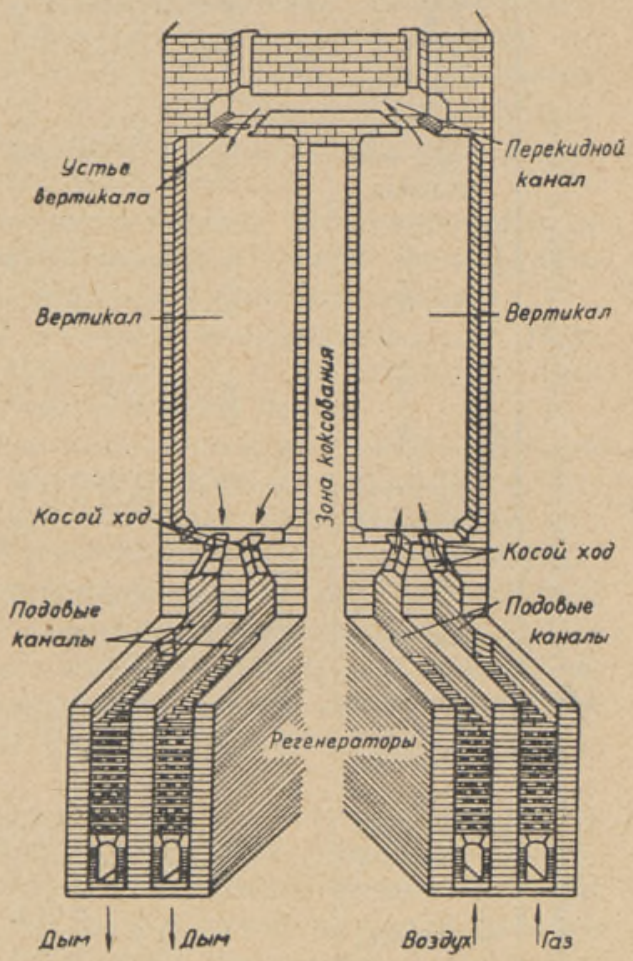

Фиг. 1. Схема обогрева печи. снизив свою температуру, газы через его устье поступают в верхнии сборный канал сопряженного простенка и, опускаясь через подобную же группу вертикалов и косых ходов сверху вниз, выходят из регенераторов, имея температуру около $300^{\circ}$.

Описанный процесс движения газов и обогрева простенков протекает в течение получаса. Затем с помощью особого кантовочного устройства направление газов в печи меняется на обратное. Теперь в те регенераторы, которые только что грелись отходящими газами и аккумулировали их тепло, направляются новые порции газа и воздуха. Нагревшись в регенераторах до температуры $800^{\circ}$ и внеся, таким образом, обратно в печь тепло, газ по выходе из косых ходов загорается в вертикалах и интенсивно обогревает уже противоположную сторону зоны коксования.

Организованный таким образом процесс происходит одновременно в 24 обогревательных простенках, сведенных в батарею (12 простенков на восходящем и 12 на нисходящем потоках).

Особенностью обогрева камерных печей, в отличие, например, от коксовых, является еще и то, что, помимо прогрева сланцевой массы вслед- 


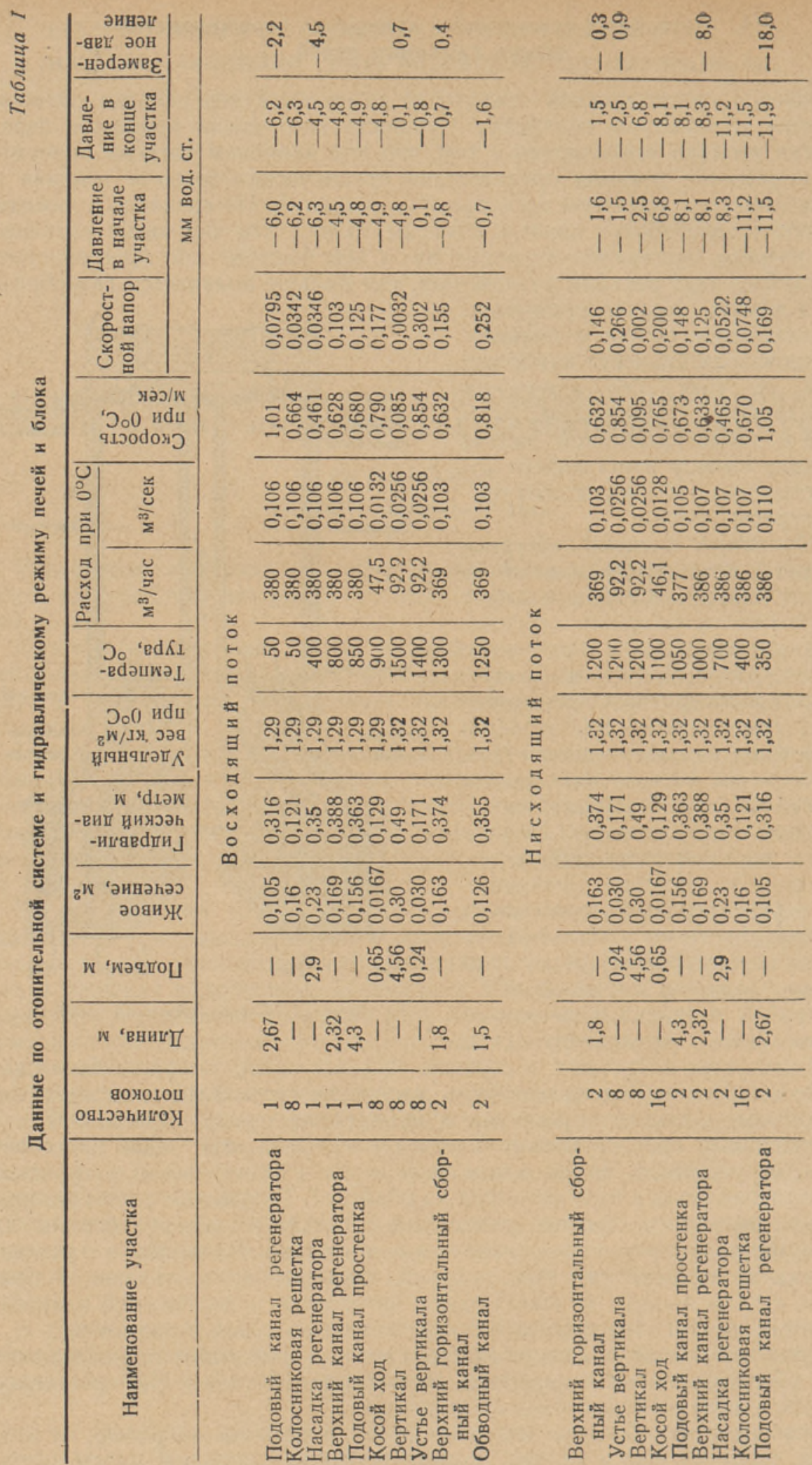


ствие теплопроводности, засыпка еще дополнительно прогревается газовым теплоносителем. Смесь раскаленных газообразных продуктов, образующихся у стен печи, при своем движении дополнительно прогревает куски сланца, находящиеся во внутренней части загрузки: В то же время в коксовых печах, как показали последние исследования $\left({ }^{11}\right)$, в массе полукокса и кокса газообразные продукты движутся в направлении от осевой плоскости к греющим стенкам камеры и, следовательно, не являются теплоносителем для кокса.

Инженерно-техническому персоналу, связанному с освоением технологического процесса производства высококалорийного газа из сланцев в камерных печах, прежде всего пришлось столкнуться с разработкой и освоением режима работы печей и регулировки отопления. Предшествующий опыт развития коксовых печей показал, что главное влияние на технологический процесс оказывает теплотехника печей. Для камерных сланцевых печей, механизмы которых не обладают большой сложностью, главной задачей явилось освоение правильного теплотехнического и гидравлического режимов.

Построенная и сданная в эксплуатацию в начале 1947 года опытная 9-камерная батарея являлась экспериментальной. На ней проводились необходимые работы по изучению технологии переработки сланца.

Так, в процессе освоения опытной батареи инженерами Г. А. Исаковым и Н. Д. Серебрянниковым (ВНИИПС) * были найдены правильные тепловой и гидравлический режимы работы печей.

В ходе работы была выяснена несостоятельность исходного проекта работы печей под напором и успешно осуществлен принцип единого гидравлического режима в распределітельных каналах по всей батарее. Положительные результаты выполненной работы позволили перенести опыт регулировки на промышленные печи и осуществить на них надлежащий режим. В таблице 1 приведены данные Теплотехстанции по отопительному и гидравлическому режимам одной из печей. Вместе с тем работа по разрешению ряда существенных вопросов, касающихся полного освоения теплотехники печей, продолжается коллективом комбината и Теплотехстанции и в настоящее время.

Камерные печи имеют большую поверхность стен, поэтому решающую роль в интенсификации теплообмена приобретает обеспечение равномерной и наибольшей допустимой температуры поверхности простенков зоны коксования. Выравнивание температуры кладки печей по длине батареи и обогревательного простенка достигается путем равномерного распределения газа и воздуха по всем простенкам и вертикалам с помощью имеющихся в печах регулировочных средств. Что же касается выравнивания температуры по высоте зоны коксования печи, то его до сих пор нельзя считать удовлетворительным.

На фиг. 2 изображена горелка проектной формы огневых вертикалов печей типа II, III и III а (опытная батарея и промышленные блоки I и II в г. Кохтла-Ярве). Как можно видеть из этой фигуры, исходная конструкция имеет ряд существенных недостатков. Во-первых, встреча потока газа и воздуха организована под углом в $44^{\circ}$, что значительно интенсифицирует процесс сжигания газа в нижней части вертикалов. Во-вторых, перед выходом в вертикал косые ходы сливаются и образуют смеситель, в котором происходит интенсивное предварительное сгорание газа, вызывающее местный перегрев пода вертикала.

Кроме того, как показала опытная наладка **, в горелке такой формы

* Всесоюзный научно-исследовательский институт по переработке сланцев.

** Автор считает своим приятным долгом выразить благодарность руководителю бригады Теплотехстанцин Н. Д. Шевкунову за предоставление возможности ознакомиться с материалами испытаний и работами по наладке камерных печей. 
нижние регистры как регулировочные средства мало эффективны, и рөгулировка ими практически затруднительна.

Эти недостатки были отмечены исследователями ВНИИПС при регулировке опытной батареи в 1948 году и затем окончательно подтверждены в первые годы эксплуатации I и II промышленных блоков.

В дальнейших работах Теплотехстанции с участием работников комбината «Кохтла-Ярве» в горелки камерных печей были внесены изменения с целью достижения возможно более равномерного обогрева камер по высоте.

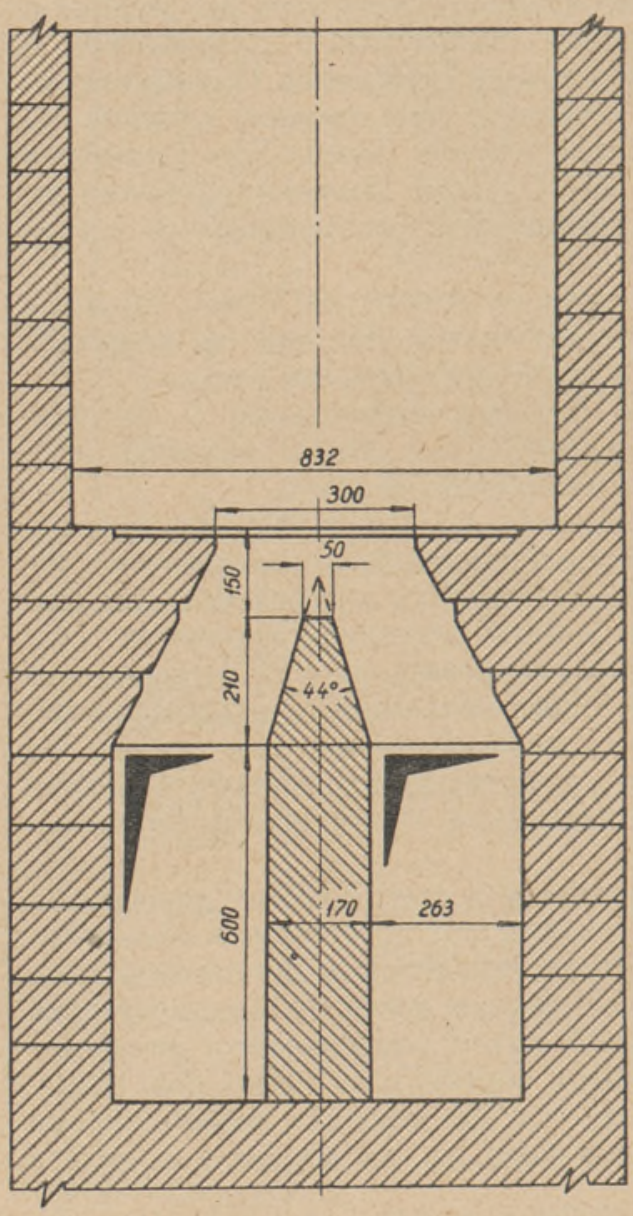

Фиг. 2. Исходная конструкция горелки по проекту для печей типа II, III и IIIa.

Первые работы в этом направлении были начаты в 1950-1951 годах на I и II блоках, а затем и на опытной батарее. На поду вертикалов, над разделительной стенкой ходов («коньком»), были установлены нижние регистры в качестве кирпичей-рассекателей потоков газа и воздуха (фиг. $3 a$ ).

Необходимо признать, что первое предложение было неудачным. Наличие зазора в $150-170$ мм между разделительной стенкой и регистром не препятствовало встрече потоков в устье, кроме того регистр, являясь препятствием для набегающих потоков газа и воздуха, интенсифицирует процесс горения.: Поэтому разность температур низа и верха обогреваемой поверхности при высоте вертикала 4,56 м оставалась без изменения $\left(\sim 180^{\circ}\right)$.

В 1953-1954 годах установленный регистр был заменен специальным кирпичом-рассекателем (фиг. 3, б). В результате этой реконструкции разность температур по высоте вертикала снизилась в среднем на $30^{\circ}$ (с 180 до $150^{\circ}$ ). В результате последних переделок конструкции горелки (фиг. 3, в) удалось снизить разность температур между верхом и низом простенка еще на $20^{\circ}$, доведя ее до $130^{\circ}$.

Уменьшение разности температур обогревательных простенков по вертикали примерно на каждые $10^{\circ}$ приводит к увеличению выхода газа на $1,5-2 \%$ и к соответственному увеличению производительности камерных печей.

Горелки проектной формы для печей типа IV (третий блок в г. Кохтла-Ярве) изображены на фиг. $4, a$ и фнг. 4 , б. В первом случае разделительная стенка возвышается над подом вертикала на 134 мм, во втором случае заканчивается на уровне пода.

При совершенно одинаковых условиях эксплуатации разность температур между верхом и низом вертикала (высотой 4,9 м) составляла 

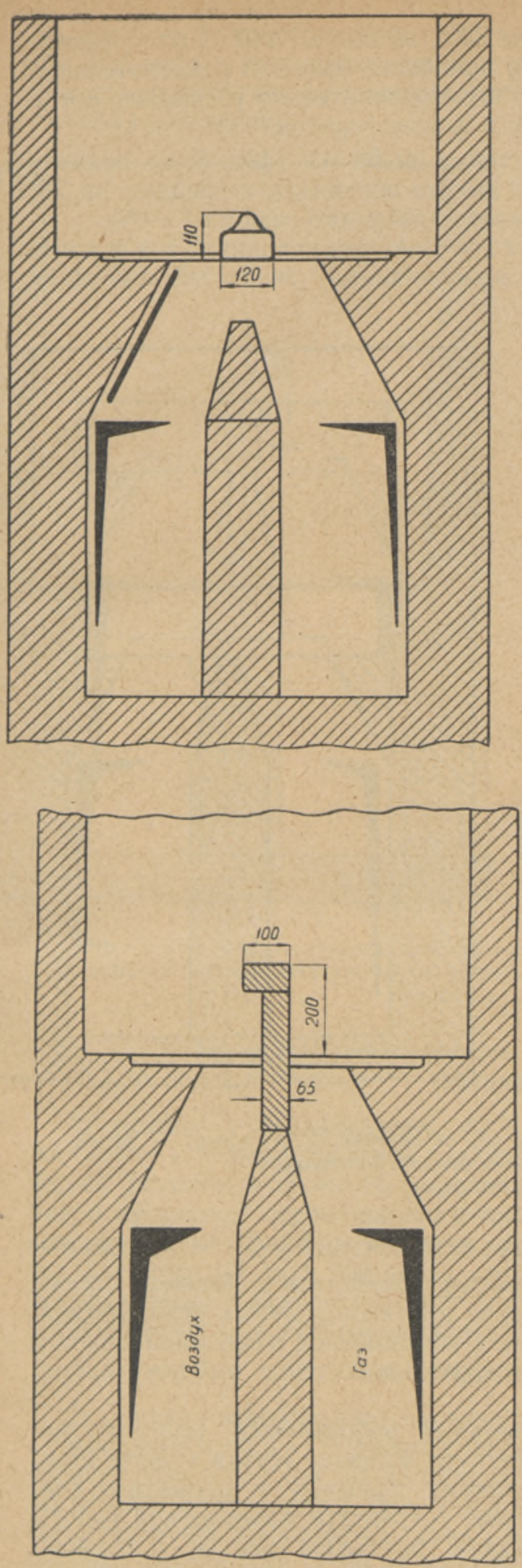

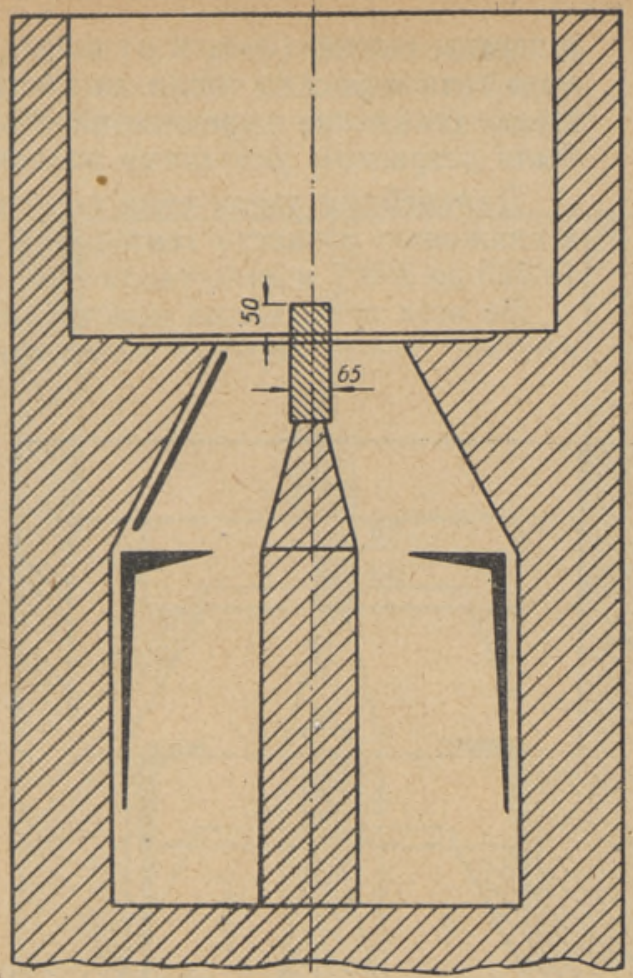

Фиг. 3. Изменения исходной конструкции горелки: $a$ (наверху слева) - установлен регистр, б (наверху справа) регистр заменен кирпичом-рассекателем, нацело разделившим потоки, в (внизу) увеличена разделительная перегородка. 
в первом случае (фиг. $4, a$ ) в среднем $220^{\circ}$, во втором $240^{\circ}$. Выход камерного газа и расход тепла на обогрев при более высокой разделительной стенке был выше в среднем на $6 \%$. В этом окончательно убедились, когда были устранены указанные различия в форме горелок.

Дальнейшее увеличение высоты стенки на 60 мм (фиг. 5, a) привело к снижению разности температур по высоте вертикала в среднем на $20^{\circ}$ (с 220 до $200^{\circ}$ ) и дало увеличение выхода камерного газа на $3-4 \%$.

Во всех испытанных конструкциях горелок, как исходных, так и измененных, факел горения вследствие неодинаковых скоростей движения
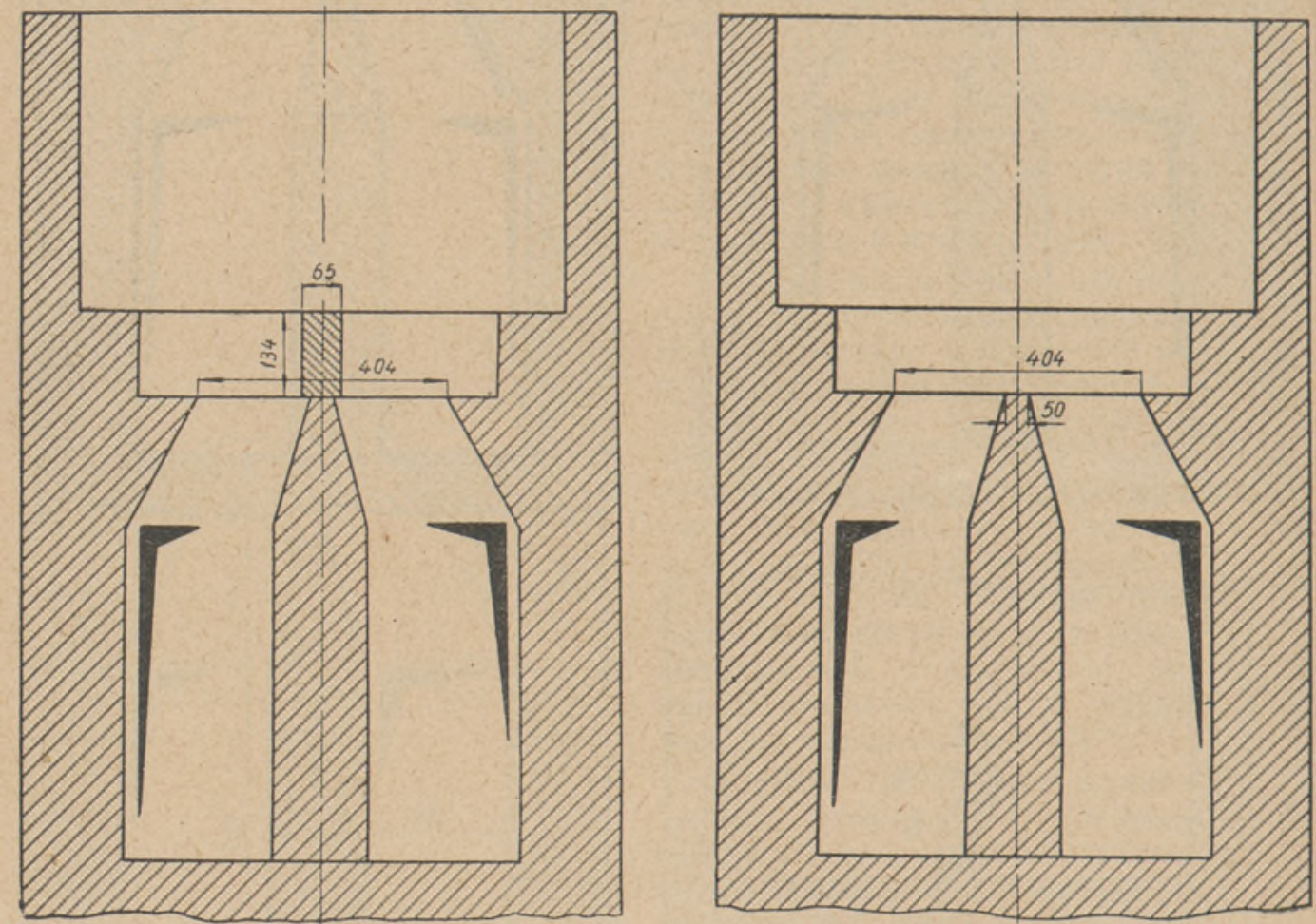

Фиг. 4. Конструкции горелки по проекту для печей типа IV. a (слева) - пятый полублок, $б$ (справа) - шестой полублок.

газа и воздуха (объемы газа и воздуха при $\alpha=1,07$ и $Q_{\mathrm{p}}^{\text {в }}=900 \mathrm{\kappa \kappa aл} / \mathrm{m}^{3}$ относятся как 1:1,2 сечения же их равны) смещался к боковой стенке, что вызывало неравномерность обогрева противоположных стен вертикала. Смещение факела удалось устранить установкой с воздушной стороны косого хода козырька на верхней разделительной стенке, как показано на фиг. $5, \sigma$.

Таким образом, инженерно-техническими работниками Теплотехстанции и комбината «Кохтла-Ярве» достигнуты большие успехи в части отопления печей, изменения их гидравлических режимов и улучшения конструкций газовых горелок. Вместе с тем, результаты проведенной работы позволяют исследователям и практикам поставить вопрос о возможности дальнейшего улучшения конструкции горелок-и позышения производительности существующих камерных печей. 
Следовательно, тормозящим моментом в процессе горения в рассматриваемом нами случае становятся физические стадии смесеобразования. Именно эти процессы при высокотемпературном горении начинают отставать по скорости протекания, задерживая и регулируя ход всего процесса в целом.

Такая область протекания процесса горения называется дифф у з и о н н о й; существенное значение для скорости процесса в ней приобретают физические факторы, как, например, характер течения газовоздушного потока, распределение скоростей, концентраций и температур в этом потоке, форма и размеры горелки и камеры, характер местной турбулентности потока, перераспределение тепла внутри потока, а также между потоком и внешней средой.

В противоположность этому, процессы горения, регулирующиеся законами химической кинетики, т. е. такими факторами, как свойства данной горючей смеси, температура и общее давление в реакционном пространстве, относятся к кинетической области горения, причем

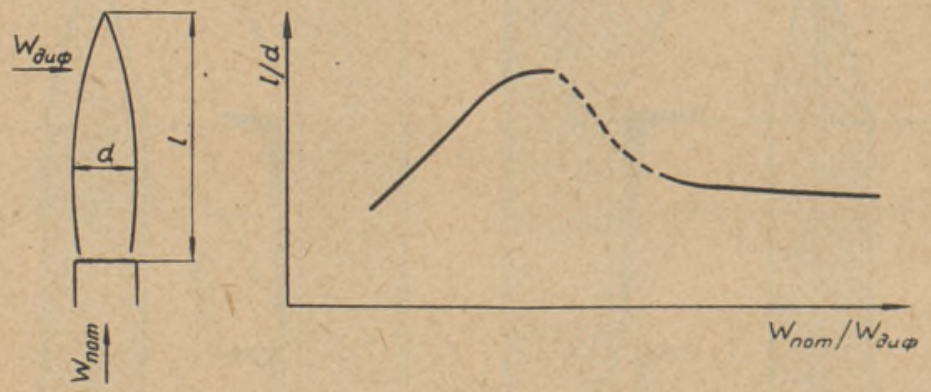

Фиг. 6. Относительная длина диффузнонного пламени.

скорость процесса горения в кинетической области не должна зависеть от факторов гидродинамического, диффузионного порядка.

Поскольку в рассматриваемом нами случае процесс-протекает в чисто диффузионной области, то можно из рассмотрения исключить воздействие кинетических факторов. Однако чисто физическая картина процесса остается все же очень сложной, тем более, что диффузионное горение в свою очередь разделяется на два вида, соответственно характеру движения газа. Различают диффузионное горение в ламинарном потоке и диффузионное горение в турбулентном потоке.

Первое определяется явлениями молекулярной диффузии, а второе явлениями молярной или турбулентной диффузии. Переход от ламинарного режима к турбулентному для диффузионного факела происходит при критической скорости и может быть иллюстрирован графиком $\left({ }^{7}\right)$, изображенным на фиг. 6. Относительная длиңа диффузионного факела (отношение длины факела $l$ к его диаметру $d$ ) должна равняться отноше-

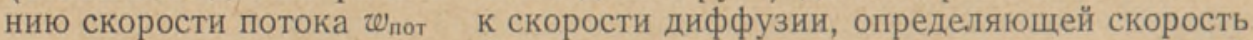

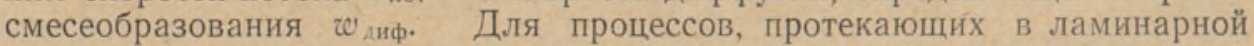
области, увеличение скорости движения потока приведет к удлинению факела пропорционально этому увеличению скорости, так как скорость молекулярной диффузии будет практически оставаться постоянной. В переходной области начнет ускоряться процесс диффузии (переход от молекулярной диффузии к турбулентной), что приведет к соответствующему укорачиванию относительной длины диффузионного факела, причем это укорачивание будет происходить до тех пор, пока не будет достигнута при достаточно развитой турбулентности пропорциональность между турбулентной диффузией и скоростью потока. 
В промышленной практике наиболее распространенным случаем диффузионного горения является горение в турбулентном потоке, при одновременном смешении газообразных струй топлива и окислителя, т. е. турбулентное горение, происходящее по мере образования горючей смеси.

Теория диффузионного горения в турбулентном потоке еще недостаточно развита. Несмотря на то, что уже давно было установлено влияние турбулентности на интенсивность процесса горения, с количественной стороны этот сложный процесс исследован недостаточно, особенно в условиях промышленных печей. Основываясь на ряде экспериментов, Д. А. Франк-Каменецкий $\left({ }^{10}\right)$ выдвинул положение о том, тто в рассматриваемом случае механизм процесса должен быть микродиффузионным. Сущность развиваемых им положений сводится к следующему. Газообразное топливо вступает в процесс в виде раздробленных объемов, окруженных воздухом. Горение происходит на их поверхности по мере образования горюче́й смеси при помощи микродиффузии.

Процесс горения в камерных печах еще более сложен для расчета, так как протекает в турбулентной и ламинарной областях.

Режим движения газа и воздуха на выходе из косого хода в вертикал камерных печей является турбулентным при значении числа Рейнольдса $\mathrm{Re} \cong 2800$, а в верхней половине вертикала движение ламинарное при $\mathrm{Re} \cong 880$.

Хотя мы и приводим здесь значение числа Рейнольдса на выходе потока из косых ходов, но должны заранее оговориться, что в данном случае процесс перемешивания газа и воздуха определяется не числом $\mathrm{Re}$, а в основном углом встречи струй. В этом можно наглядно убедиться по опытным данным M. Я. Губергрица $\left({ }^{4}\right)$. Исследуя на модели коксовой печи процессы перемешивания газа и воздуха при значениях $\operatorname{Re}$ oт 7000 до 800, M. Я. Губергриц получил интегральные кривые смешения.

Из сопоставления экспериментальных данных можно видеть, во-первых, что нет существенного различия в перемешивании потоков во всем исследованном интервале значений числа Re, a во-вторых, что в нижней части вертикала (до значений $\frac{h}{d} \cong 10$ ) перемешивается от 80 до $90 \%$ газа и воздуха. Это позволяет считать с некоторым допущением, что генераторный газ в камерных печах с косыми ходами сгорает диффузионно и в основном в турбулентном потоке.

Известно, что диффузионное турбулентное пламя короче диффузионного ламинарного пламени и создает высокие местные тепловые напряжения. Поэтому для более равномерного распределения тепла по большей поверхности необходимо применять вытянутое диффузионное пламя в ламинарном потоке. C этой точки зрения условия горения газа в вертикалах камерных печей нельзя признать благоприятными.

Здесь нельзя не остановиться на затрагиваемом некоторыми исследователями вопросе о применении горелок предварительного смешения к камерным печам. В самом деле, казалось бы налицо имеются все условия для применения таких горелок: раскаленные до $1200-1300^{\circ}$ поверхности, предварительный подогрев газа и воздуха и т. п. Некоторыми исследователями $\left({ }^{5}\right)$ даже высказывалось сожаление, что этот метод сжигания газа пока не нашел применения и что требуется большая подготовительная работа, направленная к разрешению ряда вопросов теоретического и практического порядка.

Мы полагаем, что можно дать однозначный и явно отрицательный ответ, не прибегая ни к какой предварительной теоретической и практической работе, так как известно, что горелки предварительного смешения дают короткий, сосредоточенный факел, а вся трудность задачи в подобных камерных печах сводится к созданию вытянутого диффузион- 
ного факела. Поэтому нам представляется необходимым дополнительно искусственным путем растянуть горение газа в факеле.

Без каких-либо специальных мероприятий в печах заведомо обеспечен перегрев низа простенка и недогрев верха. В коксовых печах старой конструкции с перекидными каналами (печи типа ПК) это явление приводило к ухудшению качества кокса и уменьшению получаемого при коксовании газа. Искусственное вытягивание факела в топочной системе коксовых печей обеспечивается применением рециркуляции (круговой поток) газов. При этом происходит разбавление смеси газа и воздуха инертными газами, замедляется скорость горения, пламя вытягивается на большую длину и повышается равномерность обогрева печи по высоте.

Необходимо обратить внимание на принципиальное отличие в характере распределения тепловой нагрузки коксовых и сланцевых печей по высоте, снижающее преимущества этого испытанного приема в случае камерных сланцевых печей. В коксовых печах тепловой поток более равномерен по всей высоте простенка (он определяется только распределением температуры газа), а в камерных печах имеет место неравномерность температуры по высоте засыпки (в силу противоточности движения материала и газа). Поэтому выравнивание температуры стенки в коксовых печах требует ра в н о е р н ого теплового потока по высоте простенка, а в камерных печах н е р а в н о м е р н о г о, а именно, тепловой поток по вертикали должен возрастать прямо пропорционально разности температур между газом и засыпкой. О том, что на характере распределения температур простенка по высоте не сказывается теплопроводность, а влияет только выделение тепла в факеле, можно судить как по расчетам, так и по опытам Бера и Дормана $\left({ }^{12}\right)$.

В камерных печах, следовательно, задача выравнивания температур простенков по высоте более сложна, чем в коксовых печах. Необходимо было бы так организовать горение газа, чтобы по вертикали на каждую последующую единицу длины факела выделялось все большее количество тепла.

Практически возможный процесс тепловыделения сводится к замедленному горению на выходе из горелок и растягиванию факела на всю высоту зоны коксования, с выделением большего количества тепла в верхней половине вертикала.

Несмотря на все сказанное выше, необходимо признать, что расчет горения в этих условиях является очень сложным и задача не может получить общего решения: либо не удается составить замкнутую систему дифференциальных уравнений с четким определением граничных условий, либо (при наличии такой системы уравнений) их не удается проинтегрировать без грубых упрощений, не отвечающих истннному развитию процесса.

Сложность явлений горения делает весьма трудным и всякое достаточно четкое экспериментальное исследование этого процесса, а тем более попытку широкого обобщения получаемых экспериментальных результатов. Все же единственно плодотворным путем исследования процессов горения в настоящее время является путь экспериментальный с последующим обобщением опытных данных с помощью теории подобия.

Для обоснованных предложений по реконструкции существующих горелок обратимся поэтому к данным экспериментальных исследований по перемешиванию или горению потоков применительно к рассматриваемому нами случаю. Речь идет о перемешивании или горении газовых потоков, взаимодействующих под различными углами атаки. Такие эксперименты проводили К. Руммель $\left({ }^{13}\right)$, М. А. Кузьмин $\left({ }^{8}\right)$, М. А. Глинков и Н. А. Калошин $\left({ }^{3}\right)$, П. И. Сычев $\left({ }^{9}\right)$, М. Я. Губергриц $\left({ }^{4}\right)$, А. В. Арсеев $\left({ }^{1}\right)$, Е. В. Вирозуб $\left({ }^{2}\right)$, автор $\left({ }^{6}\right)$ и другие. 
M. А. Глинковым и Н. А. Калошиным $\left({ }^{3}\right)$ приводятся данные, показывающие влияние угла встречи газовых и воздушных потоков и их скоростей на процесс перемешивания при различных толщинах перемешивающихся струй. Опыты производились с воздухом и смесью воздуха с углекислотой. Скорости струй менялись в пределах от 2 до $10 \mathrm{~m} / \mathrm{cek}$. В результате увеличения угла встречи от 0 до $90^{\circ}$ во всех случаях значительно ускорялся процесс перемешивания. Увеличение скорости потоков в изученных пределах тоже вызвало ускорение процесса перемешивания. Однако влияние скорости, по данным Глинкова и Калошина, сказывается только в пределах угла встречи от 30 до $70^{\circ}$. При углах меньше $30^{\circ}$ длина пути, на котором происходит полное перемешивание, от увеличения скорости почти не зависит. Упомянутые авторы объясняют это тем, что при встрече под углом появляются слагающие скорости, направленные перпендикулярно к оси потока и вызывающие турбулентную пульсацию, при углах же меньше $30^{\circ}$ эти слагающие малы.

Была установлена качественная зависимость между толщиной потоков и длиной пути полного перемешивания, а именно: чем толще были потоки, тем длиннее был путь, на котором достигалась полнота перемешивания, причем при возрастании угла встречи пропорциональность не сохранялась.

М. Я. Губергриц $\left({ }^{4}\right)$, как указывалось выше, проводил на модели коксовой печи исследования перемешивания газовых потоков, выходящих из косых ходов. Проведенные им опыты показали, что при режимах движения, отвечающих численным значениям Re oт 800 до 1300, т. е. при формально ламинарных режимах, процесс перемешивания все же определяется турбулизирующим воздействием встречающихся под углом струй.

Многочисленные экспериментальные исследования перемешивания газовых потоков в ограниченном пространстве были проведены К. Руммелем $\left({ }^{13}\right)$. Он исследовал перемешивание по изменению концентрации с учетом присоса из пространства, окружающего факел. Опыты ставились по выявлению влияния на перемешивание размеров камеры, абсолютных н относительных скоростей перемешивающихся потоков, их соотношения, величины сечения, формы, взаимного расположения потоков и угла встречи факела с подом печи, влияния препятствий, встречающихся на пути факела, в виде резких пережимов сечения. Однако в выводах по обширным исследованиям дается только качественная оценка проверенных факторов. Количественная оценка полноты перемешивания при том или ином сочетании факторов им не устанавливается.

К. Руммель также пришел к выводу, что перемешивание особенно улучшается при встрече потоков под углом друг к другу. Из сопоставления графиков изменения концентрации при параллельном движении потоков и под углом можно подсчитать, что перемешивание потоков под углом в $45^{\circ}$ сокращает длину факела горения примерно в полтора раза.

А. В. Арсеев (1) в Восточном научно-исследовательском институте топливоиспользования проводил исследование двух плоских потоков в прямоугольной трубе, которое позволило установить в графической форме зависимость полноты перемешивания этих потоков от длины пути перемешивания, от соотношения сечений и от условий встречи перемешивающихся потоков - от величины абсолютных и относительных скоростей потоков и от угла их встречи. Наиболее неблагоприятным случаем является перемешивание параллельных потоков равного сечения и с равными начальными скоростями. Отметим попутно, что эти же выводы подтверждают все исследователи параллельных потоков. При отклонении отношения скоростей перемешивающихся потоков от единицы, за счет изменения скорости любого потока как в сторону увеличения, так и в сторону уменьшения, среднее перемешивание улучшается. 
Из графиков в работе А. В. Арсеева можно установить, что степень перемешивания потоков, движушихся с одинаковыми скоростями под углом в $45^{\circ}$ друг к другу, превышает степень перемешивания параллельных потоков также примерно в полтора раза. Следовательно, данные Руммеля и Арсеева по перемешиванию потоков под углом, полученные в опытах, проведенных в разных условиях, оказались одинаковыми.

Итак, параллельные потоки перемешиваются хуже, чем потоки, встречающиеся под углом. Можно было бы привести дополнительно большой экспериментальный материал по перемешиванию параллельных плоских и круглых струй (струя в струе), но и сказанного вполне достаточно, чтобы прийти к выводу о необходимости отказаться от газовых горелок с косыми ходами и заменить их прямоточными.

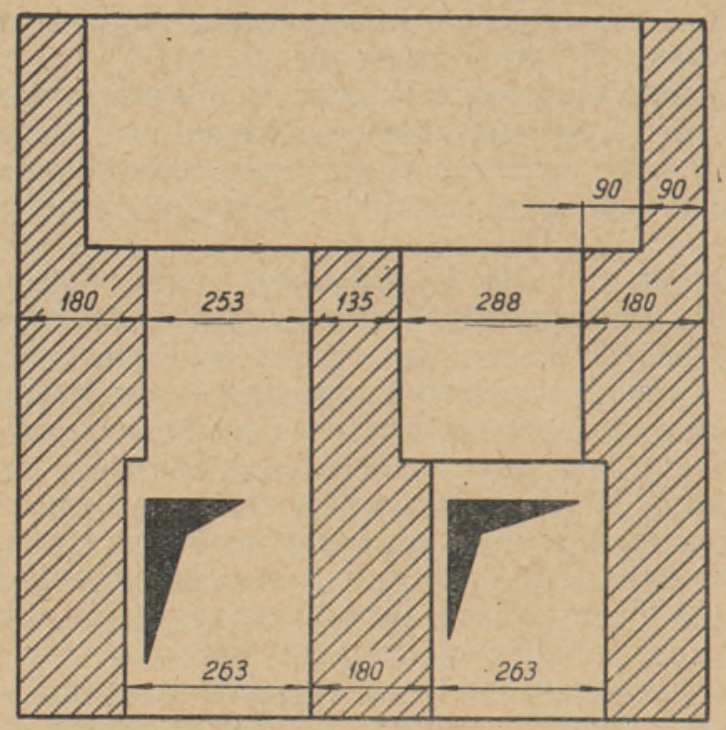

Фиг. 7. Вариант прямоточной горелки, рекомен. дованной для камерных печей.

Помимо перехода на горелки другой конструкции целесообразнолодновременно перейти и на другой режим движения - с турбулентного на ламинарный. Это приводит к диффузионному горению в ламинарном потоке, т. е. к значительному вытягиванию факела и, следовательно, к выравниванию температур по высоте простенка.

Исходя из всего изложенного и опираясь на опыт по реконструкции существующих газовых горелок, работниками сланцеперерабатывающего комбината «Кохтла-Ярве» и Теплотехстанции совместно с нами было решено опробовать прямоточные горелки с измененным режимом горения. C этой целью предложена к испытанию прямоточная горелка, изображенная на фиг. 7. Отличительными особенностями горелки по сравнению с исходной являются: 1) замена косых ходов, на прямые, 2) увеличение площади живого сечения горелки, 3) обеспечение равных скоростей газа и воздуха на выходе из горелки, 4) предельная простота конструкции и изготовления горелки (отпадает необходимость в фасонном кирпиче).

При той жё производительности горелки (см. данные таблицы 1) число Рейнольдса, подсчитанное для одного из потоков в устье прямоточной горелки, составляет величину 1700, против 2800 в горелке с косыми ходами. Это говорит о том, что в данном случае процесс горения будет 
определяться молекулярной диффузией. Время горения определяется временем молекулярного смешения, которое в этом случае равно:

$$
\tau_{\mathrm{n}} \cong \tau_{\phi} \cong \frac{\delta^{2}}{D}
$$

где $\delta$ - размер газовых частиц (пропорционален линейному размеру горелки в устье),

$D$ - коэффициент молекулярной диффузии.

В горелке с косыми ходами при $\mathrm{Re}=2800$ процесс горения определяется турбулентной диффузией, и время смешения в этом случае, практически равное времени горения, будет порядка

$$
\tau_{\phi} \simeq \frac{\delta^{2}}{A}
$$

где $A-$ коэффициент турбулентной диффузии.

Так как коэффициент $A$ много больше коэффициента $D$ (это как бы увеличенный турбулентностью коэффициент диффузии), то время сгорания в прямоточной горелке тоже будет бо́льшим. При изменении конструкции горелки нами было еще дополнительно увеличено время сгорания за счет развития линейных размеров горелки.

Все это в замысле должно растянуть факел горения по высоте простенка. Нельзя было не считаться с тем обстоятельством, что после осуществления всех изменений может произойти увеличение времени сгорания свыше среднепроточного и газ не успеет сгореть на пути своего движения в вертикале. Это обстоятельство может быть устранено установкой нижних регистров, которые могут изменять плошадь сечения горелки на выходе и тем самым регулировать длину пламени факела.

Необходимо отметить обший недостаток газораспределительной системы камерных печей, заключающийся в недостаточной величине соотношения площади поперечного сечения подовых каналов и суммарной площади косых ходов. Этот недостаток принципиально должен еше больше усугубиться при переходе на горелки с большей площадью сечения, как это мы имеем, например, в данном случае.

Выравнивание распределения газа вдоль простенков на существующих печах предполагается обеспечить за счет верхних регистров (устанавливаемых в устьях вертикалов). Так как при данной конструкции горелки перемешивание газа и воздуха произойдет на некотором расстоянии от устья, благодаря разделительной перегородке ( $b=134 \mathrm{Mм})$, то можно будет обеспечивать форсированную работу печи не опасаясь перегрева пода вертикалов. Перемешивание параллельных потөков по всей высоте простенков исключает местные перегревы и при форсированной работе печи поднимет средний уровень температуры простенков, чтө существенно скажется на увеличении производительности камерных печей и на повышении надежности их работы.

Можно ожидать, что предложенная конструкция горелки наряду с перечисленными положительными качествами обладает и рядом отрицательных; так, например, возможны трудности обеспечения равномерного распределения газа и воздуха по длине простенков.

Все это говорит о необходимости быстрейшего опробования предложенного варианта конструкции прямоточной горелки на опытной 9-камерной батарее, с тем чтобы в ходе проверки отработать ее конструкцию, а в случае надобности и частично изменить ее сечения.

При опытной проверке горелки на паре сопряженных простенков следует предусмотреть возможность опробования ее при форсированной работе. Возможно, что для этого придется в верхнем сборном коллекторе иметь давление не 0 , а порядка - 0,5 мм в. ст. В случае получения положительных результатов при опытной проверке предложенной конструк- 
циии или ее улучшенных модификаций оптимальный вариант горелки должен быть применен на печах, подлежащих перекладке, а также при разработке рабочих проектов намеченных к постройке заводов.

В заключение следует отметить, что несмотря на довольно большое количество. работ по сжиганию газа, проведенных в последние 'два десятилетия советскими и иностранными исследователями, полученные результаты имеют лишь качественный характер. Поэтому перед научными работниками стоит задача постановки широких исследований диффузионных процессов сжигания газа как в ламинарном, так и в турбулентном потоках, с тем чтобы получить количественные закономерности этих процессов, в первую очередь применительно к камерным печам.

\section{Институт энергетики Академии наук Эстонской ССР}

Поступила в редакцию 7 VII 1955

\section{ЛИТЕРАТУРА}

1. А. В. Арсеев, Сжигание промышленных газов. Методы и приборы, Металлургиздат, Свердловск-Москва, 1952, стр. $77-87$.

2. Е. В. В и розуб, Моделирование коксовых печей. Технология и теплотехника коксования, Научные труды Украинского научно-исследовательского углехимического института, т. XXVII, вып. 5, Металлургиздат, 1952.

3. М. А. Глин н ков и Н. А. К а лошин, Условия перемешивания газовых потоков, «Уральская металлургия», № 6, 1937, стр. 32-38.

4. М. Я. Г уб е рг р и ц, Смешение газовых потоков в отопительных каналах коксовых печей, Известия АН СССР, ОТН, № 5, 1950.

5. Г. И. Д еша лит, Процессы горения и теплоотдача в топочной системе коксовых печей, Металлургиздат, Харьков-Москва, 1948.

6. Ю. В. Ив а нов, Некоторые закономерности свободной круглой струи, развивающейся во внешнем поперечном потоке, Известия АН СССР, № 8, 1954.

7. Г. Ф. Кн о р е, Топочные процессы, Госэнергоиздат, М.-Л., 1951.

8. М..А. К уз в и н, Об изучении процессов горения в печах и топках на моделях, «Металлург», № 6, 1935, стр. $74-81$.

9. П. И. С ч ев, Исследование перемешивания холодных газовоздушных потоков, Сборник научно-исследовательских работ Восточного научно-исследовательского института теплонспользования, № $5,1940$.

10. Д. А. Франк-К ам енецкий, Диффузня и теплопередача в химической кинетике, Изд. АН СССР, М.-Л., 1947.

11. Н. П. Худокормов а, Направление газовых потоков в угольной загрузке при коксовании, «Сталь», № 4, 1955.

12. H. B ä hr, H. D o r m a n n, Wärmetechnischen Grundlagen der Koksofenbeheizung, Gas- und Wasserfach, $\mathrm{Nr} 44-8,1927$.

13. K. Rummel, Der Einfluss des Mischvorganges auf die Verbrennung von Gas . und Luft in Feuerungen, Archiv f. d. Eisenhüttenwesen, Heft 11, 12 1936/37 und Hefte $1-5$ 1937/38. 